$63^{\text {ème }}$ Congrès de la SFCO, 01005 (2015)

DOI:10.1051/sfco/20156301005

(C) Owned by the authors, published by EDP Sciences, 2015

\title{
CONFÉRENCE
}

\section{Greffes autologues et ostéotomies segmentaires : rôle de la vascularisation}

\author{
Khoury G \\ Paris, France \\ dr.georges.khoury@gmail.com
}

Les augmentations osseuses, classifiées en greffes, régénérations ou ostéotomies segmentaires, sont autant de possibilités thérapeutiques qui s'indiquent selon les contextes locaux et généraux (métaboliques) du patient.

Le remodelage de toute augmentation passe par un envahissement vasculaire.

Cette angiogenèse sécurise le pronostic immédiat de la procédure et influe sur le succès à court et moyen terme.

Elle dépend toutefois de la capacité angiogénique individuelle.

L'acte thérapeutique a une influence directe sur cette angiogénèse primaire et nous aborderons cette partie par une approche clinique raisonnée.

This is an Open Access article distributed under the terms of the Creative Commons Attribution License 4.0, which permits unrestricted use, distribution, and reproduction in any medium, provided the original work is properly cited. 